\title{
Changes in the levels of comet parameters before and after fluoxetine therapy in major depression patients
}

\author{
Rajeev Panwar ${ }^{1}$, M. Sivakumar ${ }^{2}$, Vikas Menon $^{3}$, Balasubramaniyan Vairappan ${ }^{4}$ \\ ${ }^{1}$ Department of Anatomy, Shri Sathya Sai Medical College and Research Institute, Nellikuppam, India, ${ }^{2}$ Department of Anatomy, Jawaharlal Institute of \\ Postgraduate Medical Education and Research (JIPMER), Puducherry, India, ${ }^{3}$ Department of Psychiatry, Jawaharlal Institute of Postgraduate Medical \\ Education and Research (JIPMER), Puducherry, India, ${ }^{4}$ Department of Biochemistry, Jawaharlal Institute of Postgraduate Medical Education and \\ Research (JIPMER), Puducherry, India
}

\begin{abstract}
Major depression belongs to mood disorders and characterized by worthlessness, no interest or happiness in any activity; lasting for atleast two weeks. Etio-pathological changes of major depression include oxidative stress leading to free radical synthesis which causes damage to carbohydrates, proteins, lipids and nucleic acids. Nucleic acid damage can be identified by either single or double strand breaks and for quantitative estimation of the same, neutral or alkaline comet assay is performed. Fluoxetine is the drug of choice for treatment of major depression having antioxidant function. In the current study eighty drug naïve major depression patients were recruited and comet parameters namely total comet length, head diameter and tail length were measured before starting the treatment and after completion of eight week fluoxetine therapy. The levels of comet parameters were higher in females than males suggesting higher prevalence of major depression among females. On categorizing into three age groups, the numbers of major depression patients belonging to 18-30 year age group were higher than 31-40 and 41-50 year age groups. All the parameters of deoxyribonucleic acid damage were reduced after eight week of fluoxetine therapy indicating that fluoxetine has anti-oxidant action along with its antidepressant properties, which cause reversal of oxidative stress induced damage occurring during major depression.
\end{abstract}

Key words: Major depression, Oxidative stress, Deoxyribonucleic acid Damage, Comet assay, Fluoxetine

Received October 20, 2019; Revised November 28, 2019; Accepted December 12, 2019

\section{Introduction}

Major depression is one sub-type of mood disorders and can be identified by presence of low esteem, feeling of no relevance or no happiness in previously interesting and pleasurable activities; lasting continuously for atleast two weeks $[1,2]$. There can be extrinsic causative factors such as genetic

Corresponding author:

Rajeev Panwar (DD

Department of Anatomy, Shri Sathya Sai Medical College and Research Institute, Nellikuppam, Tamil Nadu 603108, India

E-mail: rajeevpanwarg6@yahoo.com factors, family history and immune-inflammatory response changes or the intrinsic factors such as either infectious like herpes virus, Human immunodeficiency virus or noninfectious such as Alzheimer's disease, autoimmune diseases etc. The etiopathogenesis mainly involves the contribution of oxidative stress and immune-inflammatory modification resulting in synthesis of free radicals such as reactive oxygen species and reactive nitrogen species. The free radicals have highly reactive oxidizing properties resulting in damage to carbohydrates, nucleic acids, proteins, and lipids [3-8]. The free radicle-mediated, oxidative stress-induced DNA damage cause numerous structural changes in DNA [9]. Structural changes in DNA can be due to reaction of heme iron with hydroxyl radical in nuclear and mitochondrial DNA [10]. 
Elevated levels of breakage in DNA strands, alkali-labile sites and oxidative DNA damage in the recurrent depressive disorder patients were found by Czarny [11], which were estimated with the help of comet assay method. The principle of comet assay utilizes single cell gel electrophoresis (SCGE) technique for estimation of the migration of the damaged DNA [12]. The degree of DNA strand breakage can be identified by analyzing the percentage of DNA present in the tail [13]. The comet assay protocol was proposed by Singh et al. [14] and later simplified by Collins et al. [15].

Fluoxetine is the drug of choice for major depression causing decrease in oxidative stress-induced DNA damage and subsequent restoration of anti-oxidant function [16]. Fluoxetine inhibits serotonin re-uptake and causes continuous activation of post-synaptic receptors by serotonin and it has enhanced antioxidant capacity which partially contributed to its therapeutic efficacy $[17,18]$.

Thus study of DNA damage parameters can be valuable for investigating the grade of depression and for monitoring the treatment efficacy. Only few studies have been done in the past for the estimation of DNA damage in patients diagnosed with major depression. The current study has been aimed to estimate the DNA damage in newly diagnosed drug-naive cases of major depression and also after fluoxetine course for eight-weeks in the same patients.

\section{Materials and Methods}

The study was performed in the Department of Anatomy, Jawaharlal Institute of Postgraduate Medical Education and Research (JIPMER), Pondicherry (India) from October 2016 to March 2018. This was an interdepartmental project between the departments of Anatomy and department of Psychiatry. It was a prospective clinical study for which prior clearance was obtained from the Postgraduate Research Monitoring Committee and Institute Ethics Committee (Human Studies), respectively (approval No. JIP/IEC/2016/28/941 dated 19.10.2016).

The study recruited single group of forty drug-naïve major depression patients of 18 to 50 year age, newly diagnosed as per Diagnostic and Statistical Manual of Mental Disorders, 5th Edition criteria, attending the psychiatry out-patient department. Pregnant women, diabetics, hypertensive, cancer patients and patients under antidepressant treatment, were excluded. After explaining the procedure to the patients and legally acceptable representative and obtaining written consent, blood samples were collected before starting the treatment and after eight week fluoxetine therapy.

\section{Alkaline comet assay}

DNA damage was analyzed by using comet assay method in which SCGE technique was employed. The alkaline comet assay method standardized by Nandhakumar et al. [19] was used for the assessment of DNA damage.

\section{Principle}

The alkaline comet assay involved the movement of negatively charged damaged DNA fragments towards the anode during electrophoresis resulting in comet-like tail like appearance under the microscope.

\section{Procedure}

The comet assay is a three-day procedure consisting of blood collection to cell lysis on day one, electrophoresis and cell fixation on day two, and staining and comet scoring on day three.

\section{Day one - Blood collection, lymphocyte isolation, slide preparation and cell lysis}

A $2 \mathrm{ml}$ venous blood was taken in heparinized syringes, added to a centrifuge tube containing $2 \mathrm{ml}$ of histopaque (lymphocyte separation media) without allowing mixing of the two and subjected to centrifugation. On completion of centrifugation at $1,500 \mathrm{rpm}$ for thirty minutes, lymphocytes occupied the middle layer; plasma in the topmost layer, histopaque in lower layer and red blood corpuscles occupied the bottom. The first layer formed by coating the slide with normal melting agar (NMA), second layer consisted of mixture of lymphocytes and low melting agar (LMA) over the NMA-coated slides and the third layer formed by coating with LMA. Afterwards, slides were immersed in lysis solution leading to lysis of the cell membrane of the lymphocytes to expose the nucleoids.

\section{Day two - Electrophoresis, neutralization and cell fixation}

The slides were subjected to electrophoresis in a solution containing Sodium Hydroxide and disodium (ethylene diamine tetra acetate), without current for thirty minutes resulting in unwinding of DNA, followed by passage of current for thirty minutes leading to migration of negatively charged DNA fragments towards the anode. The slides were neutral- 
ized with trisaminomethane buffer, fixed in fixative solution and dried at room temperature overnight or 1-2 hours in the incubator at $37.9^{\circ} \mathrm{C}$ temperature.

\section{Day three - Staining, photomicrography and comet scoring}

A 40-50 randomly selected cells per stained slide were observed under the bright field microscope (Olympus BX53; lympus, Tokyo, Japan) and the captured images were utilized for comet parameter scoring using comet software (TriTek Comet Score Freeware v1.5; TriTek Co., Sumerduck, VA,

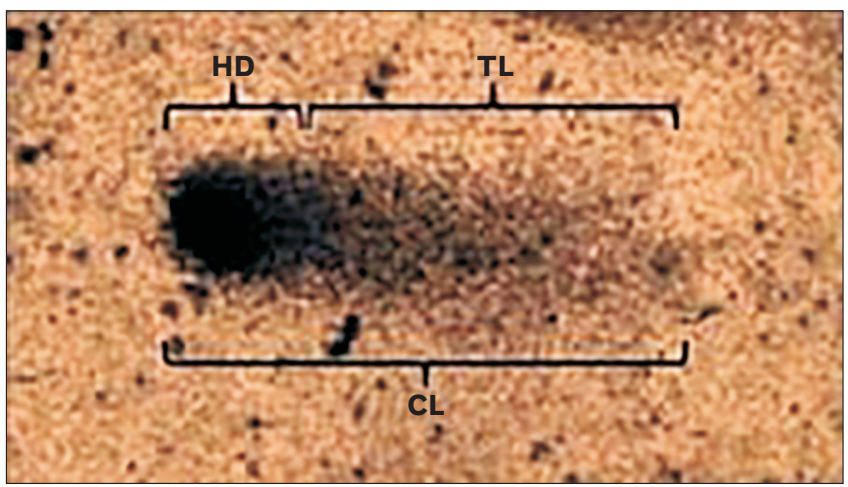

Fig. 1. Parts of comet. CL, comet length; HD, head diameter; TL, tail length.
USA). The analyzed parameters were generated as notepad file and they included Total comet length (CL) i.e. the total amount of DNA present in single lymphocyte; head diameter (HD) i.e. the amount of undamaged DNA present in the head which is not dispersed and tail length (TL) i.e. the damaged DNA which moves towards anode because of more negatively charged molecules (Figs. 1, 2).

\section{Sample size calculation and statistical analysis}

The sample size was computed using the Open Epi programme 9 open sources Epidemiology statistics for Public Health version 3.01 formula (Emory University, Atlanta, GA, USA) [20]. On assuming alpha error of 0.05 , power $90 \%$ and dropout rate of $10 \%$; the eighty patients were recruited. The comparision of categorical data before starting and after completion of the treatment, was completed by utilizing Student's paired $t$-test and Wiloxons signed ranksum test. The continuous parameters, such as age and comet parameters were expressed as mean \pm standard deviation (SD) or median with interquartile range (IQR) and the comparision of the comet parameters between the groups were carried by utilizing Student's paired $t$-test/Wiloxons signed ranksum test based on distribution of data (Normal/Non-normal). Considering $5 \%$ level of significance, $P$-value of $<0.05$ was considered as significant. PASW Statistics for Windows, Version

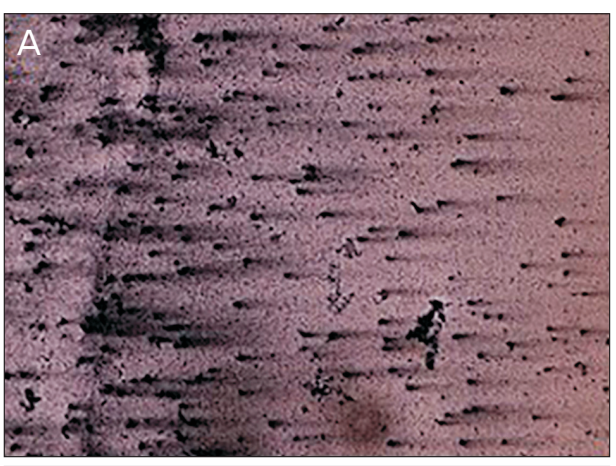

C

$\mathrm{CL}(\mu \mathrm{m}) \quad \mathrm{HD}(\mu \mathrm{m})$ $101.685394 \quad 78.651688$ $48.314606 \quad 24.719101$ $53.932583 \quad 53.932583$ $42.134830 \quad 17.977528$ $40.449440 \quad 20.224720$ $33.146069 \quad 18.539326$ $47.191010 \quad 21.910112$ $42.696629 \quad 19.101124$ $41.011234 \quad 20.224720$ $48.314606 \quad 48.314606$ $42.134830 \quad 30.337078$ 56.179775

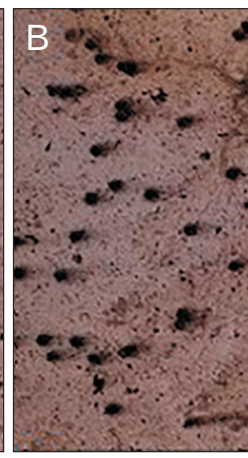

D

CL $(\mu \mathrm{m})$ 34.831459 35.955055 22.471910 33.707867 25.842697 25.280899 17.415730 26.404495 39.887642 27.528090 26.966291 25.280899

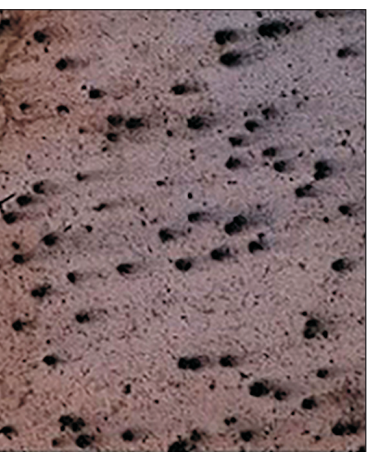

$\mathrm{HD}(\mu \mathrm{m})$ 34.831459 20.786516

17.977528

33.707867

25.842697

15.168539

16.292135

20.224720

39.887642

27.528090

18.539326

21.348314
TL $(\mu \mathrm{m})$ 0.000000

15.168539

4.494382

0.000000

0.000000

10.112360

1.123595

6.179775

0.000000

0.000000

8.426967

3.932584
Fig. 2. Comet images and comet parameter. (A, C) Before treatment $(B, D)$, after treatment. CL, comet length; HD, head diameter; TL, tail length. 
18.0 (SPSS Inc., Chicago, IL, USA) was used for statistical analysis and the charts were plotted utilizing Microsoft Excel 2007 (Microsoft, Redmond, WA, USA).

\section{Results}

Patients were categorized into three age-groups namely $18-30,31-40$, and $41-50$ years respectively, among which highest number of patients comprising of $38.8 \%$ of total patients belonged to $18-30$ years age group followed by $37.5 \%$ belonging to $31-40$ years age-group and $23.8 \%$ belonging to 41-50 years age-group, respectively (Table 1 ). The percentage of female patients (58.8\%) was significantly higher than the male patients (41.3\%) (Table 2). Among all the comet parameters, only HD followed normal distribution, remaining comet parameters i.e. CL and TL followed non-normal distribution.

Table 1. Age distribution among major depression patients

\begin{tabular}{cc}
\hline Variable & Value $(\mathrm{n}=80)$ \\
\hline Age $(\mathrm{yr})$ & \\
$18-30$ & $31(38.8)$ \\
$31-40$ & $30(37.5)$ \\
$41-50$ & $19(23.8)$ \\
\hline
\end{tabular}

Values are presented as number (\%).

Table 2. Sex distribution in major depression patients

\begin{tabular}{cc}
\hline Variable & Value $(\mathrm{n}=80)$ \\
\hline Sex & $33(41.3)$ \\
Male & $47(58.8)$ \\
Female & \\
\hline
\end{tabular}

Values are presented as number (\%).

\section{Levels of comet parameters before starting and after eight-week fluoxetine therapy}

The mean value of $\mathrm{HD}$ was 27.165 with SD of \pm 6.930 while the median values of CL and TL along with IQR were 33.919 (14.567) and 6.843 (8.579), respectively. After eight-week fluoxetine therapy, the mean value of HD was 20.324 with SD of \pm 6.451 while the median values of CL and TL along with IQR were 23.004 (5.188) and 2.000 (2.543), respectively.

The mean value of $\mathrm{HD}$ and the median values of $\mathrm{CL}$ and TL were reduced after eight-week fluoxetine therapy. However, the reduction in the levels of CL and TL was statistically significant $(P<0.001)$ and reduction in the levels of HD was statistically not significant $(P=0.002)$ (Fig. 3 ).

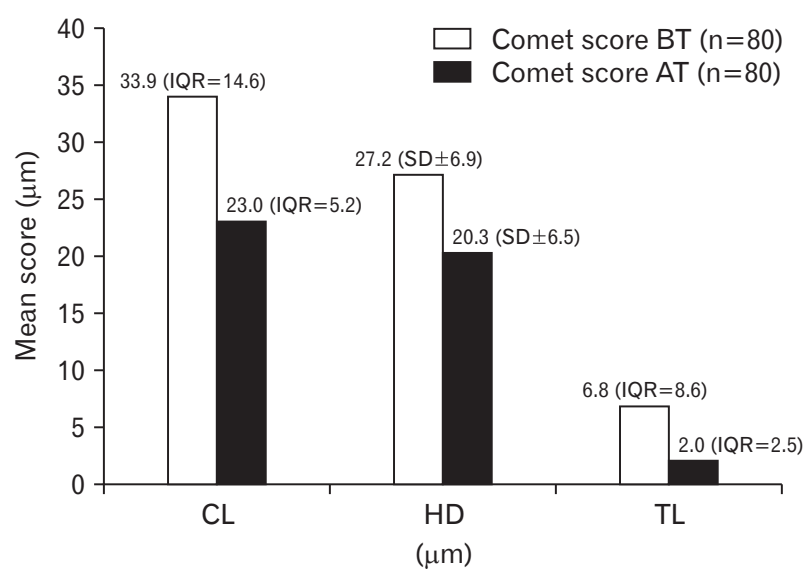

Fig. 3. Mean scores of comet parameters in major depression patients BT and AT with fluoxetine for eight weeks. AT, after treatment; BT, before treatment; CL, comet length; HD, head diameter; IQR, inter quartile range; SD, standard deviation; TL, tail length.

Table 3. Age-wise distribution of comet parameters among major depression patients before starting and after completion of the eight-week therapy with fluoxetine

\begin{tabular}{|c|c|c|c|c|c|c|}
\hline \multirow{2}{*}{$\begin{array}{c}\text { Comet } \\
\text { parameter }\end{array}$} & \multicolumn{2}{|c|}{$18-30 \mathrm{yr}$} & \multicolumn{2}{|c|}{$31-40 \mathrm{yr}$} & \multicolumn{2}{|c|}{$41-50 \mathrm{yr}$} \\
\hline & Before & After & Before & After & Before & After \\
\hline $\mathrm{CL}(\mu \mathrm{m})$ & $37.68 \pm 11.43$ & $23.77 \pm 4.16$ & $34.97 \pm 11.13$ & $22.79 \pm 5.76$ & $32.51 \pm 8.18$ & $20.93 \pm 3.90$ \\
\hline $\mathrm{HD}(\mu \mathrm{m})$ & $28.44 \pm 7.29$ & $21.49 \pm 4.90$ & $26.32 \pm 6.81$ & $19.64 \pm 5.94$ & $26.40 \pm 6.53$ & $19.48 \pm 3.95$ \\
\hline $\mathrm{TL}(\mu \mathrm{m})$ & $8.22(28.78)$ & $2.65 \pm 1.782$ & $6.54(32.60)$ & $2.45(10.61)$ & $6.21 \pm 4.43$ & $1.24(7.19)$ \\
\hline
\end{tabular}

Values are presented as mean \pm SD or median (interquartile range). CL, comet length; HD, head diameter; TL, tail length.

Table 4. Comparison of comet parameters among female and male major depression patients before starting and after completion of the eight-week therapy with fluoxetine

\begin{tabular}{lccccc}
\hline \multirow{2}{*}{ Comet parameter } & \multicolumn{2}{c}{ Female } & & \multicolumn{2}{c}{ Male } \\
\cline { 2 - 5 } \cline { 5 - 6 } & Before & After & Before & After \\
\hline Total comet length & $33.579(15.603)$ & $23.254 \pm 4.903$ & & $35.706 \pm 9.398$ & $22.024 \pm 4.739$ \\
Head diameter & $27.162 \pm 7.460$ & $20.489 \pm 5.366$ & & $27.171 \pm 6.252$ & $20.103 \pm 4.917$ \\
Tail length & $8.233 \pm 6.835$ & $2.305(3.036)$ & & $8.604 \pm 7.025$ & $1.568(2.263)$ \\
\hline
\end{tabular}

Values are presented as mean \pm SD or median (interquartile range). 


\section{Comparison of levels of comet parameters among different age groups and different sex}

Levels of all the comet parameters namely CL, HD, and TL were reduced after eight weeks treatment with fluoxetine. In all the age groups, reduction in the levels of all the parameters was statistically significant except in the age group 31-40 and 41-50 years age groups where reduction in the levels of TL were not significant. Reductions in the levels of CL, HD, and TL were statistically significant among both male and female groups (Tables 3 and 4).

\section{Discussion}

Major depression consists of isolated spells of changes in concern, intellect, psychosomatic functions manifesting over a period of atleast 2 weeks combined with intermediate symptomless periods [2]. Few hypothesis suggested oxidative stress leading to synthesis of free radicals resulting in damage to nucleic acids, lipids, carbohydrates and proteins as one of the cause of major depression [8]. As a result of oxidative stress induced damage, DNA structure is characterized by apurinic/apyrimidinic or baseless sites, cyclobutane-type pyrimidine dimer, chemical alteration in small bases, distortion in helix structure or breaks in single strands and double strands etc. [9]. Excessive heme iron released as a result of oxidative-stress induced-hemolysis reacts with hydroxyl radical leading to single or double-strand breaks in nuclear and mitochondrial DNA [10]. Czarny [11] estimated elevated levels of breakage in DNA strands, alkali-labile sites and oxidative DNA damage in the recurrent depressive disorder patients the help of comet assay method. SCGE technique is used during comet assay for estimation of the migration of the damaged DNA [12]. On the passage of current, there is migration of relaxed DNA loops from nucleus towards the anode, giving an appearance of the comet tail. Collins et al. [15] suggested a single layer of agarose gel for cell-embedding on a plain slide pre-coated with agarose and dried. The breaks in single strand or double-strand DNA can be assessed quantitatively by comet assay; either neutral or alkaline [14].

The lifetime risk of major depressive disorders in United States was highest in the age-group 45-64 years (15.91\% with standard error i.e. $\mathrm{SE} \pm 0.50$ ), followed by age groups $30-44$ years (14.03\% with $\mathrm{SE} \pm 0.46)$ and $18-29$ years (12.02\% with SE \pm 0.49$)$ [21]. Reddy and Chandrashekar [22] suggested highest prevalence of mental disorder in 35-44 year age group, depression being highest among the all mental disorders (41.7\%) and higher prevalence of depression among indian females than the male counterparts (female: 49.9\%, male: 40.5\%). Judd et al. [23] reported higher occurrence of major depression in females as compared to males (female: 60.6\%, male: 39.4\%). Present study showed highest prevalence of the major depression in 18-30 year age-group (38.8\%), closely followed by $31-40$ year age-group (37.5\%) and higher prevalence of major depression in females than the males.

In the current study, comet images had good comet tails and higher CL, HD, and TL in the cases before the treatment than after concluding the treatment. The breaks in the DNA strands resulted in liberation of supercoils leading to migration of the fragmented DNA towards the anode. Hence, TL is believed to be the best indicator of DNA damage [24, 25]. Different parameters such as TL, tail movement (TM), percentage of DNA in tail (\%T), olive tail movement (OTM) have been scrutinized in the past as indicators of DNA damage in the cases before and after the interventions [26-29]. The therapeutic agent (fluoxetine) had antioxidant effect which resulted in decrease in TL after completion of the treatment.

The available literature about assessment of the levels of parameters of oxidative stress in the cases before and after treatment with fluoxetine in major depression patients was limited. Galecki et al. explained the role of fluoxetine in influencing the antioxidant defences by estimating superoxide dismutase and catalase, malondialdehyde and Hamilton depression rating scale (HDRS) scores and it showed significant reduction in the HDRS scores on completion of fluoxetine therapy [30].

Fluoxetine is preferred drug for major depression because of its action post-synaptic receptors by prolonging activation of the receptors and delaying the re-uptake of serotonin [31]. Novío et al. [16] demonstrated a decrease in oxidative stressinduced damage and restoration of anti-oxidant function caused by fluoxetine. Zafir and Banu [18] suggested antioxidant properties of fluoxetine. Perić et al. [17] suggested the role of fluoxetine in GSH-dependent defense systems along with decrease in levels of pro-inflammatory cytokines in socially isolated mice.

Czarny [11] assessed the degree of endogenous damage to the DNA in individuals having recurrent depressive disorder (rDD) and healthy subjects, DNA damage due to hydrogen peroxide and changes occurring in DNA damage parameters 
after repair incubation and reported considerably greater endogenous DNA damage in the rDD patients than the healthy subjects $(P<0.001)$ which was indicated by the increased $\% \mathrm{~T}$. DNA damage after exposure to $\mathrm{H}_{2} \mathrm{O}_{2}$ was substantially more in the patients than the controls $(P<0.001)$. Post-incubation analysis showed complete repair of $\mathrm{H}_{2} \mathrm{O}_{2}$-induced DNA damage in the controls but in the patients, the damage to the DNA was still more than the endogenous DNA damage levels $(P<0.001) .11$ The current study showed fluoxetine as antioxidant agent in addition to its antidepressant action; as there was notable reduction in TL in the cases along with symptomatic relief.

For assessing the oxidative stress induced cellular damage by alkaline comet assay among the psychiatric diseases, other than depression, one study was done among schizophrenia patients [32]. The levels of parameters of DNA damage were analyzed among cases and controls and again these values were compared after incubating the cells in the nutrient medium among the cases. The DNA damage parameters namely CL, HD and TL were reduced after the repair incubation in the cases.

The stratification of all the comet parameters was done based on gender and different age groups and the widest disparity between pre and post-treatment levels of CL, HD, and TL was found in the 18-30 year age-group. In both the genders, the changes in the levels of all the comet parameters before starting and after completing eight-week fluoxetine therapy were statistically significant.

The current study established relationship between age and oxidative stress because varying levels of different comet parameters were reported among different age groups and there were differences in efficiency of mechanisms for repairing the oxidative stress-induced DNA damage in different age groups.

In conclusion, adult patients who were suffering from major depression, had increased levels of DNA damage parameters before starting the treatment which were reduced after finishing the eight-week antidepressant therapy with fluoxetine. The levels of the parameter indicated damage to the DNA were more in males than in the females.

\section{ORCID}

Rajeev Panwar: https://orcid.org/0000-0001-8684-7533

M. Sivakumar: https://orcid.org/0000-0001-7950-9827

Vikas Menon: https://orcid.org/0000-0001-8035-4658
Balasubramaniyan Vairappan:

https://orcid.org/0000-0003-1708-4864

\section{Author Contributions}

Conceptualization: RP, MS. Data acquisition: RP, VM, BV. Data analysis or interpretation: RP, MS, VM, BV. Drafting of the manuscript: RP, MS. Critical revision of the manuscript: RP, MS, VM, BV. Approval of the final version of the manuscript: all authors.

\section{Conflicts of Interest}

No potential conflict of interest relevant to this article was reported.

\section{Acknowledgements}

The funds for the study were supplied as intramural grant from the institute (sanction circular number JIP/Res/IntraMD-MS/phase2/grant3/2016-17 and JIP/Res/Intramural/ IInd year Grant/2017-18) which were utilized for the purchase of test equipments and consumables.

\section{References}

1. Akiskal HS. Mood disorders: historical introduction and conceptual overview. In: Sadock BJ, Sadock VA, Ruiz P, editors. Kaplan \& Sadocks comprehensive textbook of psychiatry. 10th ed. Philadelphia: Wolters Kluwer; 2017. p. 4099-139.

2. American Psychiatric Association. Diagnostic and statistical manual of mental disorders: DSM-5. 5th ed. Arlington, VA: American Psychiatric Association; 2013.

3. Pattanayak RD, Sagar R. Depressive disorders in Indian context : a review and clinical update for physicians. J Assoc Physicians India 2014;62:827-32.

4. Song C, Kenis G, van Gastel A, Bosmans E, Lin A, de Jong R, Neels H, Scharpé S, Janca A, Yasukawa K, Maes M. Influence of psychological stress on immune-inflammatory variables in normal humans. Part II. Altered serum concentrations of natural anti-inflammatory agents and soluble membrane antigens of monocytes and T lymphocytes. Psychiatry Res 1999;85:293303.

5. Maes M. Major depression and activation of the inflammatory response system. Adv Exp Med Biol 1999;461:25-46.

6. Maes M, Galecki P, Chang YS, Berk M. A review on the oxidative and nitrosative stress (O\&NS) pathways in major depression and their possible contribution to the (neuro)degenerative processes in that illness. Prog Neuropsychopharmacol Biol 
Psychiatry 2011;35:676-92.

7. Inal ME, Kanbak G, Sunal E. Antioxidant enzyme activities and malondialdehyde levels related to aging. Clin Chim Acta 2001;305:75-80.

8. Filomeni G, Ciriolo MR. Redox control of apoptosis: an update. Antioxid Redox Signal 2006;8:2187-92.

9. Rao KS. Genomic damage and its repair in young and aging brain. Mol Neurobiol 1993;7:23-48.

10. Lloyd RV, Hanna PM, Mason RP. The origin of the hydroxyl radical oxygen in the Fenton reaction. Free Radic Biol Med 1997;22:885-8.

11. Czarny P, Kwiatkowski D, Kacperska D, Kawczyńska D, Talarowska M, Orzechowska A, Bielecka-Kowalska A, Szemraj J, Gałecki P, Śliwiński T. Elevated level of DNA damage and impaired repair of oxidative DNA damage in patients with recurrent depressive disorder. Med Sci Monit 2015;21:412-8.

12. Collins AR. The comet assay for DNA damage and repair: principles, applications, and limitations. Mol Biotechnol 2004;26: 249-61.

13. Shaposhnikov SA, Salenko VB, Brunborg G, Nygren J, Collins AR. Single-cell gel electrophoresis (the comet assay): loops or fragments? Electrophoresis 2008;29:3005-12.

14. Singh NP, McCoy MT, Tice RR, Schneider EL. A simple technique for quantitation of low levels of DNA damage in individual cells. Exp Cell Res 1988;175:184-91.

15. Collins AR, Dusinská M. Oxidation of cellular DNA measured with the comet assay. Methods Mol Biol 2002;186:147-59.

16. Novío S, Núñez MJ, Amigo G, Freire-Garabal M. Effects of fluoxetine on the oxidative status of peripheral blood leucocytes of restraint-stressed mice. Basic Clin Pharmacol Toxicol 2011;109:365-71.

17. Wong DT, Bymaster FP, Engleman EA. Prozac (fluoxetine, Lilly 110140), the first selective serotonin uptake inhibitor and an antidepressant drug: twenty years since its first publication. Life Sci 1995;57:411-41.

18. Zafir A, Banu N. Antioxidant potential of fluoxetine in comparison to Curcuma longa in restraint-stressed rats. Eur J Pharmacol 2007;572:23-31.

19. Nandhakumar S, Parasuraman S, Shanmugam MM, Rao KR, Chand P, Bhat BV. Evaluation of DNA damage using single-cell gel electrophoresis (Comet Assay). J Pharmacol Pharmacother 2011;2:107-11.

20. Yager S, Forlenza MJ, Miller GE. Depression and oxidative damage to lipids. Psychoneuroendocrinology 2010;35:1356-62.

21. Hasin DS, Goodwin RD, Stinson FS, Grant BF. Epidemiology of major depressive disorder: results from the National Epidemiologic Survey on Alcoholism and Related Conditions. Arch Gen Psychiatry 2005;62:1097-106.

22. Reddy VM, Chandrashekar CR. Prevalence of mental and behavioural disorders in India : a meta-analysis. Indian J Psychiatry 1998;40:149-57.

23. Judd LL, Akiskal HS, Maser JD, Zeller PJ, Endicott J, Coryell W, Paulus MP, Kunovac JL, Leon AC, Mueller TI, Rice JA, Keller MB. A prospective 12-year study of subsyndromal and syndromal depressive symptoms in unipolar major depressive disorders. Arch Gen Psychiatry 1998;55:694-700.

24. Azqueta A, Slyskova J, Langie SA, O'Neill Gaivão I, Collins A. Comet assay to measure DNA repair: approach and applications. Front Genet 2014;5:288.

25. Lorenzo Y, Costa S, Collins AR, Azqueta A. The comet assay, DNA damage, DNA repair and cytotoxicity: hedgehogs are not always dead. Mutagenesis 2013;28:427-32.

26. Kopjar N, Garaj-Vrhovac V, Milas I. Assessment of chemotherapy-induced DNA damage in peripheral blood leukocytes of cancer patients using the alkaline comet assay. Teratog Carcinog Mutagen 2002;22:13-30.

27. Wood JP, Smith AJ, Bowman KJ, Thomas AL, Jones GD. Comet assay measures of DNA damage as biomarkers of irinotecan response in colorectal cancer in vitro and in vivo. Cancer Med 2015;4:1309-21.

28. Patton WP, Chakravarthy U, Davies RJ, Archer DB. Comet assay of UV-induced DNA damage in retinal pigment epithelial cells. Invest Ophthalmol Vis Sci 1999;40:3268-75.

29. Wang Y, Xu C, Du LQ, Cao J, Liu JX, Su X, Zhao H, Fan FY, Wang B, Katsube T, Fan SJ, Liu Q. Evaluation of the comet assay for assessing the dose-response relationship of DNA damage induced by ionizing radiation. Int J Mol Sci 2013;14:2244961.

30. Gałecki P, Szemraj J, Bieńkiewicz M, Florkowski A, Gałecka E. Lipid peroxidation and antioxidant protection in patients during acute depressive episodes and in remission after fluoxetine treatment. Pharmacol Rep 2009;61:436-47.

31. Perić I, Stanisavljević A, Gass P, Filipović D. Fluoxetine reverses behavior changes in socially isolated rats: role of the hippocampal GSH-dependent defense system and proinflammatory cytokines. Eur Arch Psychiatry Clin Neurosci 2017;267:737-49.

32. Muraleedharan A, Menon V, Rajkumar RP, Chand P. Assessment of DNA damage and repair efficiency in drug naïve schizophrenia using comet assay. J Psychiatr Res 2015;68:47-53. 